\title{
Chemical Modification Effect on the Mechanical Properties of Coir Fiber
}

\author{
Samia S. Mir ${ }^{*}$, Syed M. N. Hasan, Md. J. Hossain, and Mahbub Hasan \\ Department of Materials and Metallurgical Engineering, Bangladesh University of Engineering and \\ Technology, Bangladesh \\ E-mail:mir1.samia@gmail.com*
}

\begin{abstract}
Coir fiber is derived from the husk of the coconut (Cocos nucifera). Coir has one of the highest concentrations of lignin, which makes it stronger. In recent years, wide range of research has been carried out on fiber reinforced polymer composites. The aim of the present research is to characterize brown single coir fiber for manufacturing polymer composites reinforced with characterized fibers. Adhesion between the fiber and polymer is one of factors affecting the strength of manufactured composites. In order to increase the adhesion, the coir fiber was chemically treated separately in single stage (with $\mathrm{Cr}_{2}\left(\mathrm{SO}_{4}\right)_{3} \cdot 12\left(\mathrm{H}_{2} \mathrm{O}\right)$ ) and double stages (with $\mathrm{CrSO}_{4}$ and $\mathrm{NaHCO}_{3}$ ). Both the raw and treated fibers were characterized by tensile testing, Fourier transform infrared (FTIR) spectroscopic analysis, scanning electron microscopic analysis. Tensile properties of chemically treated coir fiber was found higher than raw coir fiber, while the double stage treated coir fiber had better mechanical properties compared to the single stage treated coir fiber. Scanning electron micrographs showed rougher surface in case of the raw coir fiber. The surface was found clean and smooth in case of the treated coir fiber. Thus the performance of coir fiber composites in industrial application can be improved by chemical treatment.
\end{abstract}

Keywords: Coir natural fiber, chemical treatment, span length, tensile properties.

ENGINEERING JOURNAL Volume 16 Issue 2

Received 2 November 2011

Accepted 17 January 2012

Published 1 April 2012

Online at http://www.engj.org

DOI:10.4186/ej.2012.16.2.73 


\section{Introduction}

Coir fiber composites have recently attracted a considerable attention in the composite materials research community as well as in industry. In recent years, wide range of research has been carried out on fiber reinforced polymer composites [1-10]. This is due to a range of potential advantages of coir fibers, such as low specific weight, producible with low investment at low cost, friendly processing, good thermal and acoustic insulating properties. The main constituents of coir fiber are $5.25 \%$ water soluble, $3.00 \%$ pectin and related compounds, $0.25 \%$ hemicellulose, $45.84 \%$ lignin, $43.44 \%$ cellulose and $2.22 \%$ ash. The main objectives of the current work are to characterize raw and chemically treated coir fibers and determine their tensile properties. Chemical treatments of two types were performed. Basic chromium sulfate solution treatment ( $\mathrm{pH}$ 2.5-3); performed by a 3 hours shaking the coir fibers in $4 \% \mathrm{CrSO}_{4}$ solution . The second treatment was performed by continuation of the basic $\mathrm{CrSO}_{4}$ treatment by addition of $0.02 \% \mathrm{NaHCO}_{3}$ solution and another 2 hours shaking. In $\mathrm{CrSO}_{4}$ treatment, process fibers were in pickled state at $\mathrm{pH} 3$ or lower. At this low $\mathrm{pH}$ affinity of $\mathrm{Cr}$ for coir fiber's cellulose was moderate, allowing penetration of chrome into fiber. After proper penetration, absorption was achieved and $\mathrm{pH}$ was raised. This brings about change in both $\mathrm{Cr}$ salts and fiber and causes a reaction between them. This process involves several simultaneous competing reactions.

\section{Experimental}

\subsection{Chemical treatment of coir fiber}

The Coir fibers were initially collected and cleaned. For single stage treatment, a solution of $0.5 \%$ chromium sulfate with $2 / 3$ drops of $\mathrm{HCl}$ was prepared. An initial $\mathrm{pH}$ of 2.5-3 was maintained (during reaction this $\mathrm{pH}$ became 8-9). Coir fiber was taken into the prepared solution and shaken for 3 hours. After 3 hours reaction the fiber is washed properly in distilled water. For two stages $\mathrm{CrSO}_{4}$ and $\mathrm{NaHCO}_{3}$ treatment, the same procedure was followed with an addition of $0.02 \% \mathrm{NaHCO}_{3}$ solution. The solution along with coir fiber was shaken for another 2 hours. Later the fiber was washed properly with distilled water.

\subsection{Tensile testing}

Tensile testing was performed for the span length of $5 \mathrm{~mm}, 15 \mathrm{~mm}, 25 \mathrm{~mm}$ and $35 \mathrm{~mm}$ using a tensile testing machine. The fibers were glued in between two paper frame (Fig. 1) to conform a good gripping and straight direction to the test clamps. Diameter of single fiber was measured using a scanning electron microscope (SEM). The paper frame was carefully placed in between the jaws of the load cell. The load cell and cross-head speed used were $50 \mathrm{~N}$ and $4 \mathrm{~mm} / \mathrm{min}$ respectively.

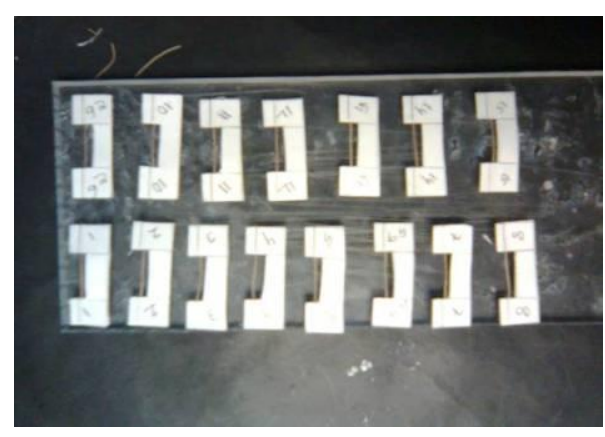

Fig. 1. Specimens for tensile test.

\subsection{Scanning electron microscopy}

The surface morphology of raw and treated coir fiber was investigated using a scanning electron microscope. The micrographs are shown and discussed in the following section. 


\subsection{FTIR spectroscopy}

The infrared spectra of coir fiber were recorded on a Nicolet 380 spectrophotometer with co-addition of 32 scans. The infrared spectra of raw fiber were measured by scratching a fiber with a knife and collecting some powdered sample. Then potassium bromide $(\mathrm{KBr})$, which acts as a reagent, was mixed (at a ratio $\mathrm{KBr}$ : Sample $=100: 1)$ with them in a mortar pestle. The mixture was then taken in a dice of specific dimensions. The pellet was formed by pressing with a hand press machine and was placed on the sample holder. The IR spectrum obtained in this study is presented in the result and discussion section.

\section{Results and Discussion}

\subsection{Tensile properties of coir fiber}

Coir fiber was characterized by evaluating the effect of variation of span length on tensile properties. The Young's modulus, strain to failure and tensile strength were measured for span length of $5 \mathrm{~mm}, 15 \mathrm{~mm}$, $25 \mathrm{~mm}$ and $35 \mathrm{~mm}$ with the help of stress/ strain curves (Fig. 2 and Fig. 3).

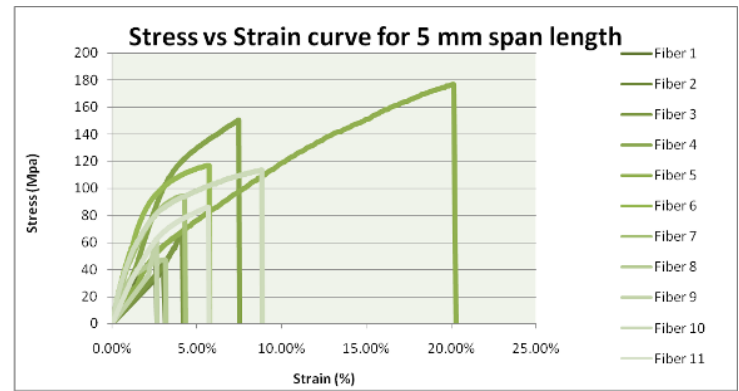

Fig. 2. Stress vs. strain curve ( $5 \mathrm{~mm}$ span length) for basic $\mathrm{Cr}_{2}\left(\mathrm{SO}_{4}\right)_{3}$ treated coir fiber of 11 samples.

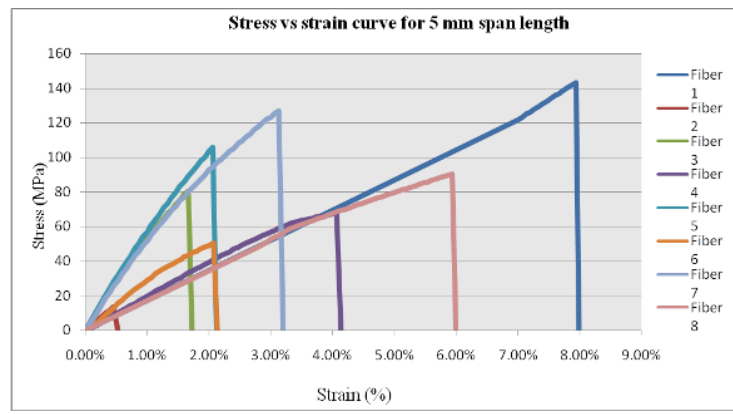

Fig. 3. Stress vs. strain curve (5 $\mathrm{mm}$ span length) for basic $\mathrm{Cr}_{2}\left(\mathrm{SO}_{4}\right)_{3}$ and $\mathrm{NaHCO}_{3}$ treated coir fiber of 8 samples.

\section{Correction of Tensile Properties:}

Corrected E-modulus and Strain to Failure can be calculated by the following steps [11]

1) $\alpha \mathrm{i}=\Delta \mathrm{L}$ total $/ \mathrm{F}-\mathrm{L} 0 / \mathrm{E} 0$. Ai

2) $\Delta \mathrm{L}$ total $/ \mathrm{F}=\varepsilon . \mathrm{L} 0 / \sigma . \mathrm{Ai}=1 / \mathrm{E} . \mathrm{L} 0 / \mathrm{Ai}$

3) Strain correction-

a) $\Delta$ L grip $/ \mathrm{Lo}=\alpha 1(\mathrm{~A} \mathrm{i} . \sigma) / \mathrm{Lo}$

b) $\Delta \mathrm{L}$ fiber $/ \mathrm{Lo}($ Corrected $)=(\Delta \mathrm{L}$ Total $/ \mathrm{L} \mathrm{o}-\Delta \mathrm{L}$ grip $/ \mathrm{Lo})$

where $\alpha \mathrm{i}$ is machine displacement for each fiber, L0 is original span length, $\mathrm{E}$ is the Young's modulus for each fiber, E0 is extrapolated Young's modulus, $\mathrm{Ai}$ is cross-sectional area for each fiber, $\mathrm{F}$ is force, $\varepsilon$ is strain and $\sigma$ is stress. Comparison between corrected and uncorrected results is shown in Table 1, 2 and 3. The average Young's modulus found is very close to extrapolated values after correction. 
For both single stage treatment and double stage treatment, the corrected and uncorrected curves ( 1 /span vs. the Young's modulus, tensile strength and strain to failure) for the span length of $5 \mathrm{~mm}, 15 \mathrm{~mm}$, $25 \mathrm{~mm}$ and $35 \mathrm{~mm}$ are shown in Fig. 4 to 13 respectively, while the same properties for raw, single stage (basic $\mathrm{CrSO}_{4}$ treated) and double stage (basic $\mathrm{CrSO}_{4}$ and $\mathrm{NaHCO}_{3}$ ) chemically treated coir fiber are shown in Tables 1 to 3 respectively.

The corrected Young's modulus values are plotted against the span length and are shown in Fig. 5 for single stage chemical treatment and in Fig. 9 for double stage chemical treatment. The corrected Young's module values found were almost constant with variation of span length.

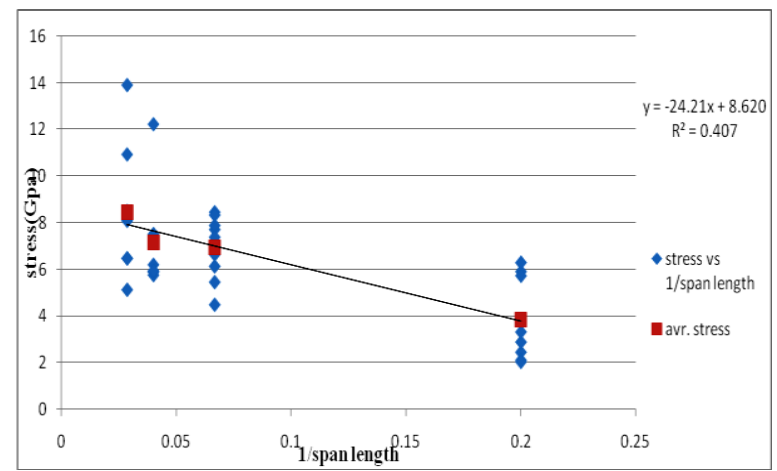

Fig. 4. Young's modulus vs. 1/span (uncorrected).

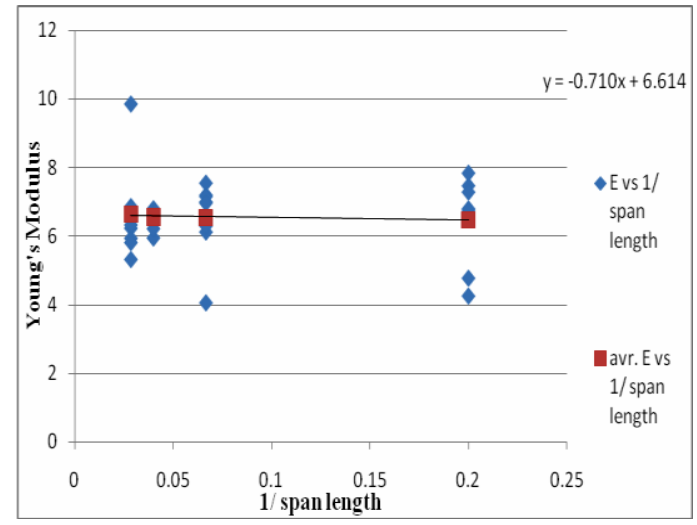

Fig. 5. Young's modulus vs. 1/span (corrected).

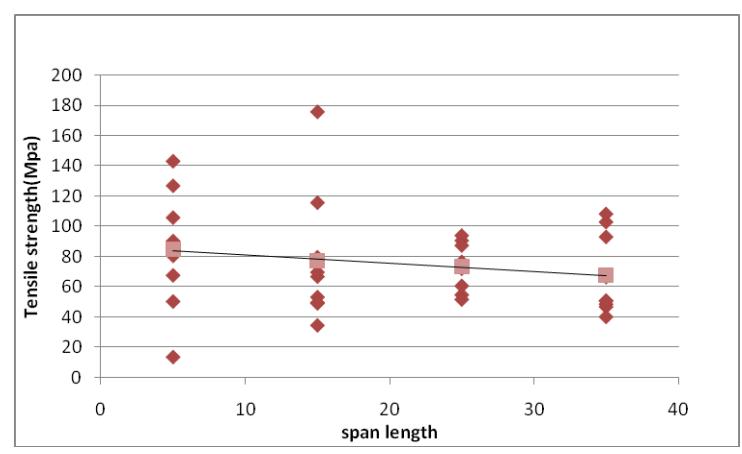

Fig. 6. Tensile strength vs. span length. 


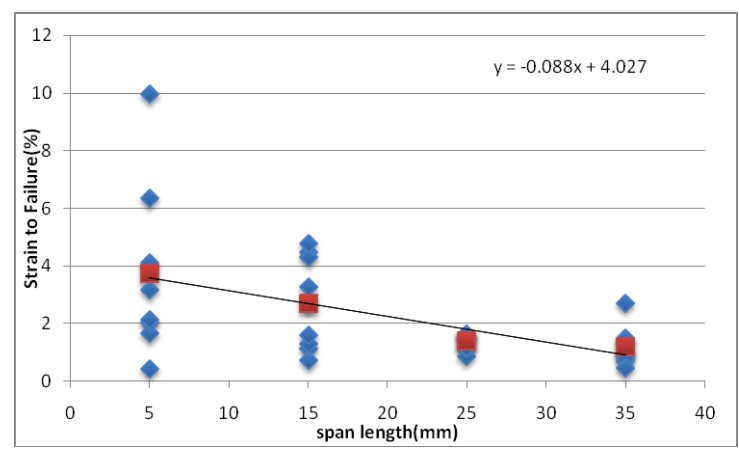

Fig. 7. Strain to failure vs. span length.

It seems that with an increase in span length, the Young's modulus increased. On the other hand, the tensile strength and strain to failure decreased with an increase in span length [12]. As mentioned by Bledski and Gassan, the longer the stressed distance of the natural fiber, the more inhomogenities will be in the stressed fiber segment, weakening the structure [11]. Thus the strength decreased with clamping length. For the fiber modulus, however, the situation is reverse. As no extensometer can be used in current set-up and machine displacement is used for the modulus determination, at longer gauge lengths, the relative effect of slippage in the clamps will be smaller.

Table 1. Tensile properties for raw coir fiber.

\begin{tabular}{lcccr}
\hline $\begin{array}{l}\text { Span } \\
\text { Length } \\
(\mathbf{m m})\end{array}$ & $\begin{array}{c}\text { Young's } \\
\text { Modulus } \\
\mathbf{( G P a )}\end{array}$ & $\begin{array}{c}\text { Corrected } \\
\text { Young's } \\
\text { Modulus } \\
\mathbf{( G P a )}\end{array}$ & $\begin{array}{c}\text { Tensile } \\
\text { Strength } \\
\mathbf{( M P a )}\end{array}$ & $\begin{array}{r}\text { Strain } \\
\text { to } \\
\text { Failure } \\
\mathbf{( \% )}\end{array}$ \\
\hline 5 & 3.69 & 4.36 & 50.4 & 5.1 \\
15 & 6.52 & 4.42 & 48.1 & 2.3 \\
25 & 6.87 & 4.45 & 40.92 & 2.21 \\
35 & 8.33 & 4.48 & 37.5 & 2.03 \\
\hline
\end{tabular}

Table 2. Tensile properties for $\mathrm{CrSO}_{4}$ treated coir fiber.

\begin{tabular}{lcccr}
\hline $\begin{array}{l}\text { Span } \\
\text { Length }\end{array}$ & $\begin{array}{c}\text { Young's } \\
\text { Modulus } \\
(\mathbf{G P a})\end{array}$ & $\begin{array}{c}\text { Corrected } \\
\text { Young's } \\
\text { Modulus } \\
\mathbf{( G P a )}\end{array}$ & $\begin{array}{c}\text { Tensile } \\
\text { Strength } \\
\mathbf{( M P a )}\end{array}$ & $\begin{array}{r}\text { Strain } \\
\text { Failure } \\
\text { (\%) }\end{array}$ \\
\hline 5 & 3.83 & 6.48 & 84.8 & 3.73 \\
15 & 6.93 & 6.54 & 77.2 & 2.70 \\
25 & 7.15 & 6.56 & 73.51 & 1.41 \\
35 & 8.45 & 6.63 & 67.6 & 1.19 \\
\hline
\end{tabular}

From Tables 1 and 2, it is found that the single stage chemically treated coir fiber had improved properties compared to the raw coir fiber. The Young's modulus increased with inceasing span length and showed higher values compared to the raw coir fiber for respective span length. 


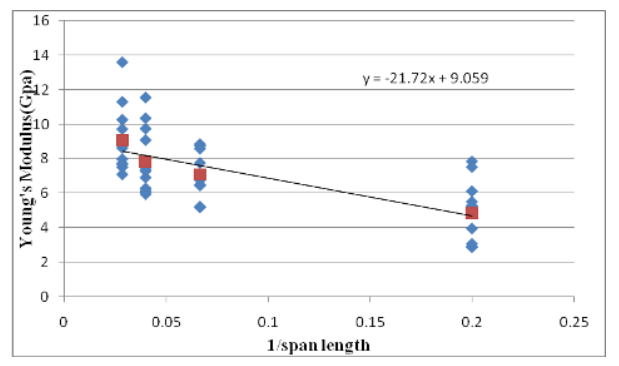

Fig. 8. Young's modulus vs. 1/span (uncorrected).

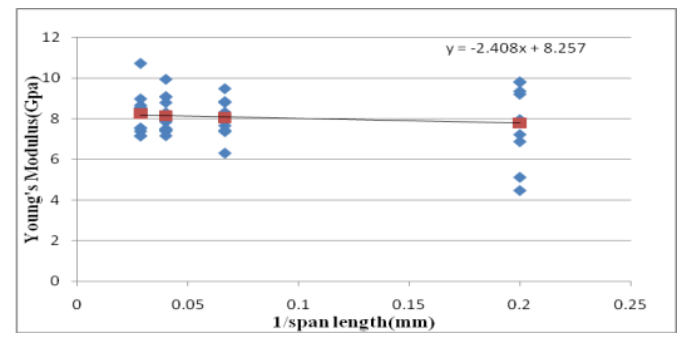

Fig. 9. Young's modulus vs. 1/span (corrected).

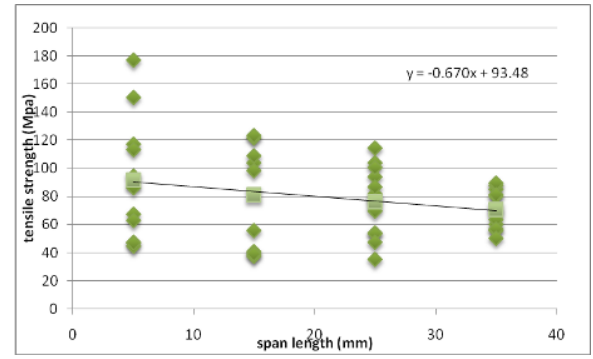

Fig. 10. Tensile strength vs. span length.

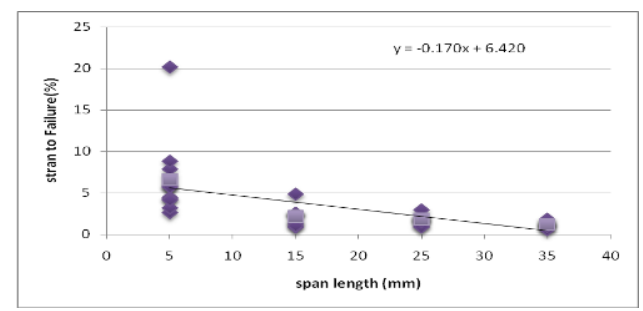

Fig. 11. Strain to failure vs. span length.

Figures 8 to 11 show that the Young's modulus increased, while the tensile strength and strain to failure decreased with an increase in span length after two stage chemical treatment. 
Table 3. Tensile properties for basic $\mathrm{CrSO}_{4}$ and $\mathrm{NaHCO}_{3}$ treated coir fiber.

\begin{tabular}{lcccr}
\hline $\begin{array}{l}\text { Span } \\
\text { Length } \\
(\mathbf{m m})\end{array}$ & $\begin{array}{c}\text { Young's } \\
\text { Modulus } \\
\mathbf{( G P a )}\end{array}$ & $\begin{array}{c}\text { Corrected } \\
\text { Young's } \\
\text { modulus } \\
\mathbf{( G P a )}\end{array}$ & $\begin{array}{c}\text { Tensile } \\
\text { Strength } \\
\mathbf{( M P a )}\end{array}$ & $\begin{array}{r}\text { Strain } \\
\text { Failure } \\
\text { (\%) }\end{array}$ \\
\hline 5 & 4.83 & 7.79 & 91.6 & 6.62 \\
15 & 7.11 & 8.05 & 80.97 & 2.18 \\
25 & 7.85 & 8.14 & 76.46 & 1.80 \\
35 & 9.11 & 8.24 & 70.88 & 1.23 \\
\hline
\end{tabular}

It is found from Tables 1 to 3 that the double stage treated coir fiber had better properties compared to the single stage treated and raw coir fibers. After a total of 5 hours treatment, the corrected Young's modulus of coir fiber was higher compared to the same of single stege treated coir fiber and was almost twice as much as the Young's modulus of the raw fiber. A thin coating layer was forrmed on the fiber surface after single stage chemical reaction between basic $\mathrm{CrSO}_{4}$ and fiber. Again after double stage chemical treatment, an even thicker coating was formed on the fiber surface due to chemical reaction between basic $\mathrm{CrSO}_{4}$ and $\mathrm{NaHCO}_{3}$ and fiber.

The chemical reactions between cellulose of coir fiber and basic $\mathrm{CrSO}_{4}$ and $\mathrm{NaHCO}_{3}$ are shown in Fig. 10. The stages of $\mathrm{CrSO}_{4}$ cross linking reactions are as follows:

a) The chrome complexes have reacted with the fiber cellulose carboxyl groups.

b) As $\mathrm{pH}$ of the solution is increased, sulfate associated with the chromium becomes displaced by the hydroxyl groups.

c) The hydroxyl groups become shared by chromium atoms.

The activity of chromium still remained incomplete after the single stage chemical treatment; as a result the tensile properties increased less over the raw coir fiber. However after the double stage treatment chromium became fully occupied in reducing hydroxyl groups, which in turn increased the tensile properties of coir fiber compared to both raw and single stage treated coir fibers (Fig. 12). The Shaking time is very important. The reaction rate accelerates during shaking. Shaking in solution also cleans the fiber surface.

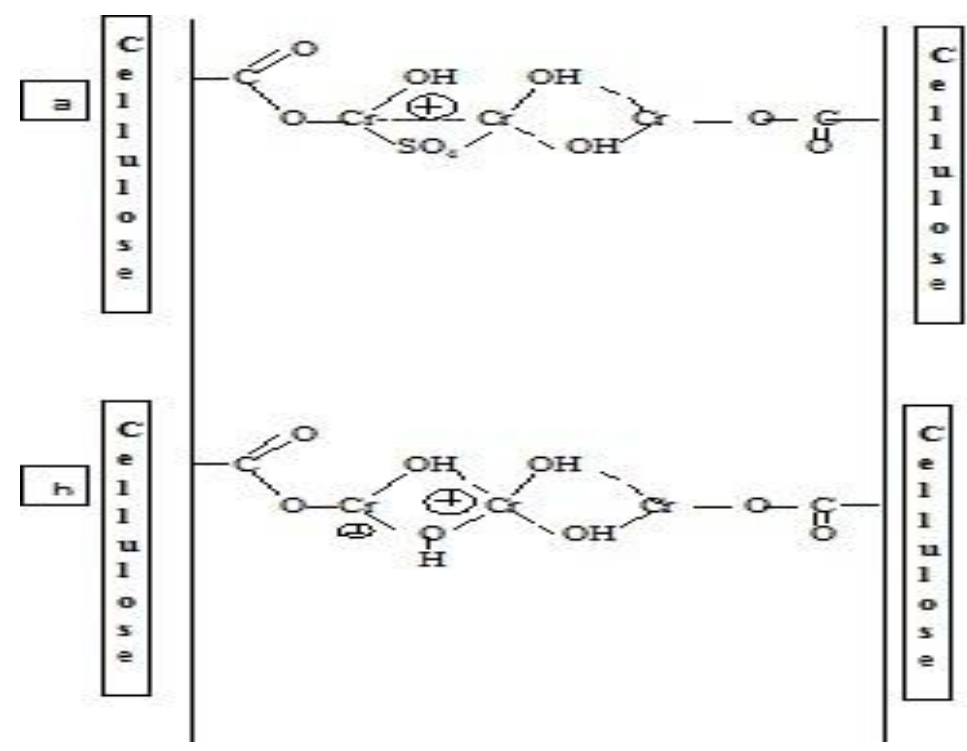

Fig. 12. Chemical reaction between cellulose of coir fiber and basic $\mathrm{CrSO}_{4}$ and $\mathrm{NaHCO}_{3}$.

\subsection{Surface morphology of raw and treated coir fiber}

Scanning electron microscope (SEM) was used to investigate the surface morphology of coir fibers. Figs. 13 to 15 show the structure of raw, single stage chemical treated and double stage chemical treated coir fiber 
respectively. It is observed that double stage chemical treated coir fiber had smoother and compact structure compared to the raw and single stage chemical treated coir fiber. Raw coir fiber had rough and porous surface compared to chemical treated fibers. Single stage chemical treatment provided a thin smooth layer on fiber surface, while the double chemical treatment provided an ever thicker and smoother coating on the coir fiber surface. As a result double stage chemical treated coir fiber had larger diameter compared to the single chemical treated coir fiber.

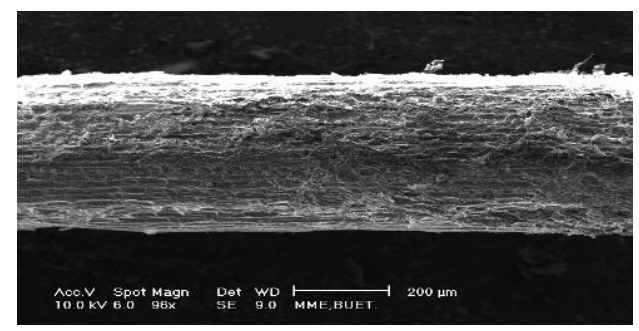

Fig. 13. SEM image of raw coir fiber.

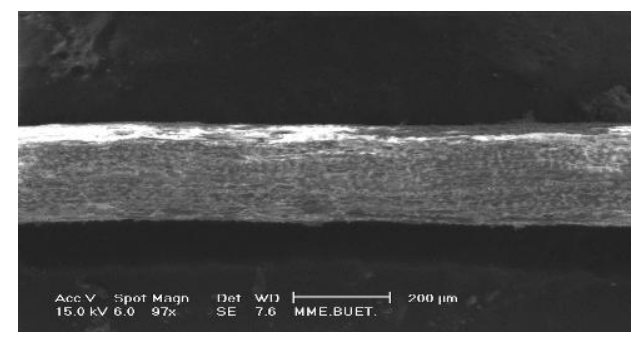

Fig. 14. SEM image of single stage chemical treated coir fiber.

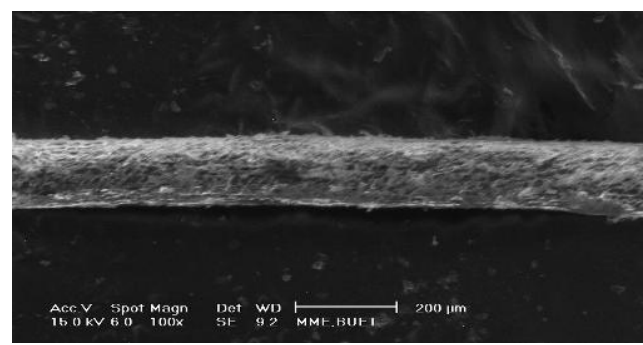

Fig. 15. SEM image of double stage chemical treated coir fiber.

\subsection{FTIR spectroscopic analysis of coir fiber}

The FTIR spectrum of raw coir fiber is shown in Fig. 15. The peak assignments of the absorption bands corresponding to various groups are summarized in Table 1, which are quite similar to the literature value [13-16]. 


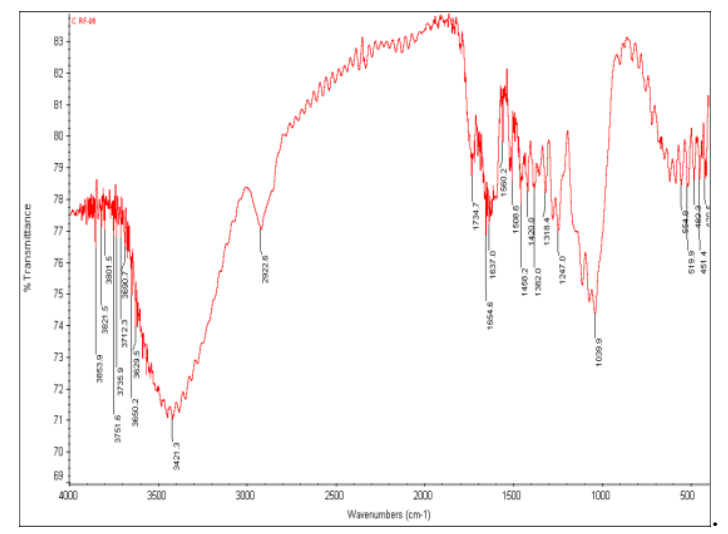

Fig. 16. FTIR spectrum of raw coir fiber.

Table 4. FT-IR spectral data of raw coir fiber $[13,17]$.

\begin{tabular}{ll}
\hline Position / cm & \multicolumn{1}{c}{ Possible Assignment } \\
\hline$\sim 3600-3200$ & $\nu(\mathrm{OH})$ broad, strong band from the cellulose, hemicellulose and lignin of coir \\
$\sim 3000-2900$ & $\nu(\mathrm{C}-\mathrm{H})$ in aromatic rings and alkanes \\
$\sim 1732.7$ & $\nu(\mathrm{C}=\mathrm{O})$ most probably from the lignin and hemicelluloses \\
$\sim 1608.5$ & $\nu(\mathrm{C}=\mathrm{C})$ aromatic in-plane \\
$\sim 1512.6$ & $\nu(\mathrm{C}=\mathrm{C})$ aromatic skeletal ring vibration due to lignin \\
$\sim 1464.2$ & $\delta(\mathrm{C}-\mathrm{H}) ; \delta(\mathrm{C}-\mathrm{OH}) 1^{0} \& 2^{0}$ alcohol \\
$\sim 1426.6$ & $\delta(\mathrm{C}-\mathrm{H})$ \\
$\sim 1375.4$ & $\delta(\mathrm{C}-\mathrm{H})$ \\
$\sim 1267.4$ & $\delta(\mathrm{C}-\mathrm{OH})$ out-of-plane \\
$\sim 1046.0$ & $\nu(\mathrm{C}-\mathrm{OH}) 2^{0}$ alcohol \\
$\sim 898.5$ & $\nu(\mathrm{C}-\mathrm{O}-\mathrm{C})$ in plane symmetric \\
\hline
\end{tabular}

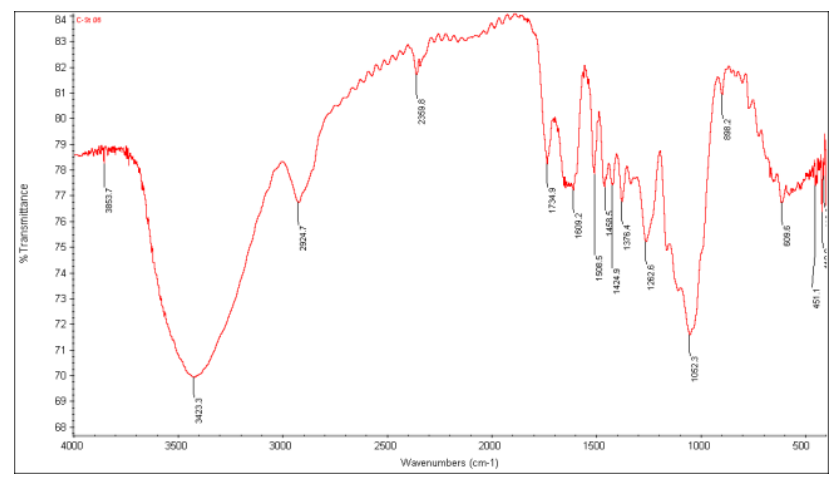

Fig. 17. FTIR spectrum of basic $\mathrm{CrSO}_{4}$ treated coir fiber.

Sharp peak was found for $\mathrm{OH}$ stretching vibration with $3421.3 \mathrm{~cm}^{-1}$ wave number (Fig. 16) in raw coir fiber. The basic $\mathrm{CrSO}_{4}$ treatment shows absorption peak with wave number $3423.3 \mathrm{~cm}^{-1}$ (Fig. 17). 


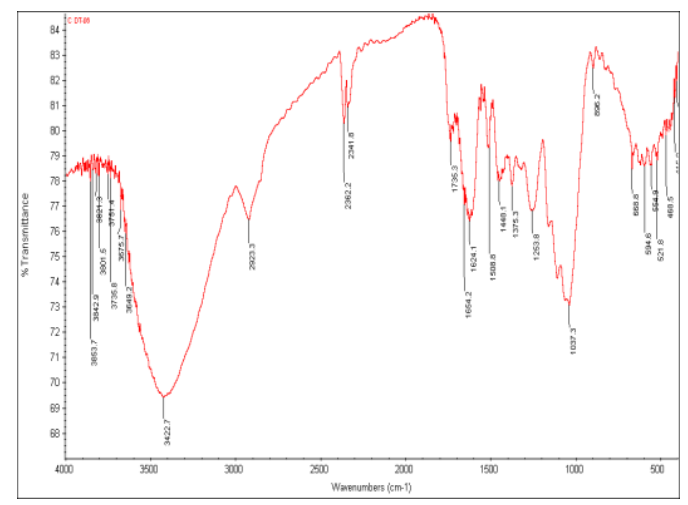

Fig. 18. FTIR spectrum of basic $\mathrm{CrSO}_{4}$ and $\mathrm{NaHCO}_{3}$ treated coir fiber.

In double stage treatment basic $\mathrm{CrSO}_{4}$ and $\mathrm{NaHCO}_{3}$ treated coir fiber $\mathrm{OH}$ stretching vibration was found with $3422.7 \mathrm{~cm}^{-1}$ wave number (Fig. 18).

\section{Conclusion}

The Young's modulus of raw treated coir fiber increased with increase in span length, while the tensile strength and strain to failure of the same decreased with increase in span length. The surface of raw coir fiber was a bit rough and porous; while the surface of double stage chemical treated coir fiber was found compact and smoother. Chemical treatment improves the tensile properties of coir fiber. Double stage chemical treatment showed better properties compared to the single stage chemical treatment. During single stage treatment basic $\mathrm{CrSO} 4$ reacts with fiber cellulose, so a thin layer formed on fiber surface which make it smooth and compact. In double stage treatment after 3 hours treatment with basic $\mathrm{CrSO} 4$ again $\mathrm{NaHCO} 3$ is added and another reaction takes place during 2 hours shaking. Here two chemical agents basic (CrSO4 again NaHCO3) react with the fiber cellulose, so that a thick and smoother layer is formed on fiber surface. Clearly it can say that both treatments improve the surface morphology but the double stage treatment provides the better then single stage treatment. However, both treatments improve the chemical bonding of coir fiber which results good mechanical properties then the raw fiber. In these two treatments the shaking time is very important to improve the reaction rate. Shaking provides the full reaction of fiber with chemical reagent and cleans the fiber surface.

\section{Acknowledgement}

The authors would like to thank Bangladesh University of Engineering and Technology (BUET), Dhaka, Bangladesh for their financial support during present research.

\section{References}

[1] B. C. Mitra, R. K. Basak, and M. Sarkar, "Studies on jute-reinforced composites, its limitation, and some solutions through chemical modification of fibres," J. App. Poly. Sci., vol. 67, no. 6, pp. 10931100, 1998.

[2] A. N. Netravali, "Ramie fiber reinforced natural plastics," Nat. Fib. Plas. Comp., pp. 321-343, 2004

[3] A. Kelly, "Composite material," J. Cer. Proc. Res., vol. 2, no. 2, pp 147-154, 2004.

[4] P. Wambua, J. Ivensand, and I. Verpost, "Natural fiber: Can they replace glass in fibre reinforced plastic?," Comp. Sci.Tech., vol. 63, no. 9, pp. 1259-1264, 2003.

[5] A. C. N. Singleton, "On themechanical properties, deformation and fracture of a naturalfiber/recycled polymer composite," Comp. B, vol. 34, no. 5, pp. 519-526, 2003.

[6] M. T. Moe and K. Liao, "Durability of bamboo-glass reinforced polymer matrix hybrid composites," Comp. Sci. Tech., vol. 63, pp. 375-387, 2003. 
[7] E. M. F. Aquino, L. P. S. Sarmento, and W. Oliveira, "Moisture effect on degradation of jute/glass hybrid composites," Rein. Plas. Comp., vol. 26, no. 2, pp. 219-233, 2007.

[8] M. T. Moe, "Effects of environmental aging on the mechanical properties of bamboo-glass fiber reinforced polymer matrix hybrid composites," Comp. A, vol. 33, pp. 43-52, 2002.

[9] Y. Seena, "A comparison of the mechanical properties of phenol formaldehyde composites reinforced with banana fibers and glass fibers," Comp. Sci. Tech., vol. 62, pp. 1857-1868, 2002.

[10] G. Kalaprasad and J. Kuruvilla, "Influence of short glass fiber addition on the mechanical properties of sisal reinforced low density polyethylene composites," J. Comp. Mat., vol. 31, no. 5, pp. 509-527, 1997.

[11] K. Bledzki and J. Gassan, "Composites reinforced with cellulose based fibers," Progress in Polymer Science, vol. 24, pp. 221-274, 1999.

[12] S. Biswas, Q. Ahsan, I. Verpoest, and M. Hasan, "Effect of span length on the tensile properties of natural fibers," Advanced Materials Research, vol. 264-265, pp. 445-450, 2011.

[13] R. M. Silverstein and G. C. Bassler, Spectroscopic Identification of Organic Compounds, 2nd ed. New York: John Wiley and Sons, Inc.

[14] M. N. Haque, H. P. S. A. Khalil, and C. A. S. Hill. "Chemical modification of wood flour and thermo mechanical pulp fiber with acetic anhydride," Journal of the Timber Development Association of India, vol. 54, no. 3, pp. 25-33.

[15] P. Garside and P. Wyettt. (2005, Jan.). Identification of cellulosic fibers by FTIR spectroscopy I: thread and single fiber analysis by attenuated total reflectance. Studies in Conservation. [Online]. 48(4), pp. 269-275. Available: http://eprints.soton.ac.uk/14069/

[16] X. H. Li, Y. Z. Meng, S. J. Wang, A. V. Rajulu, and S. C. Tjong, "Completely biodegradable composites of poly(propylene carbonate) and short, lignocelluloses fiber Hildegardia populifolia," Journal of Polymer Science, Part B: Polymer Physics, vol. 42, no. 4, pp. 666-675, 2004.

[17] M. M. Haque, M. R. Rahman, M. N. Islam, M. M. Huque, and M. Hasan, "Mechanical properties of polypropylene composites reinforced with chemically treated coir and abaca fiber," J. Reinforced Plastic and Composites, vol. 29, pp. 2253, 2010. 
